\title{
Correspondence
}

\section{Clash of the Titans}

Sir: In my letter which you kindly published under the above heading (Psychiatric Bulletin), September 1995, 19, 574) the following passage appears: "But then it occurred to me that were a piece of great pottery to be included in an MRCPsych examination paper, it would probably be described by the candidates as showing classical schizophrenic thought disorder..."

Some of your readers may have wondered how a piece of pottery could be included in an MRCPsych examination paper, or how it could show schizophrenic thought disorder. Would the piece-possibly an item from Freud's noted collection of Egyptian antiquities - be placed on a table at the front of the examination hall, or would each candidate, perhaps, be provided with a small facsimile?

The disappointingly mundane answer to these intriguing questions is that "pottery" represents a typesetting error and should have read "poetry".

I. G. Bronks

Consultant Psychiatrist,

27 Friar Gate, Derby DE1 1BY

\section{The Collegiate Trainees Committee's position on Overseas Doctors Training scheme (ODTS)}

Sir: It was encouraging to read the Collegiate Trainees Committee's (CTC) position on Overseas Doctors Training Scheme (Psychiatric Bulletin. July 1995, 19, 455-459). The recommendations of the Committee represent a significant advance for the Overseas Trainees as the scheme or the training needs of its members have not even been considered in major policy documents previously, e.g. the Statement on Training Scheme for General Professional Training (Royal College of Psychiatrists, 1994).

One of us (SF) recently completed training on ODTS, while the other author (MHM) has the experience of sponsoring a number of trainees on ODTS and monitoring their progress. From our experience we wholeheartedly support the recommendation by the CTC that overseas doctors should be allowed to spend part of their training in higher training posts. The relevance of four years of general professional training for overseas trainees has been questioned in the past and similar changes have been advocated (Holman, 1994; Farooq, 1994). The Committee has also rightly pointed out that Membership examination may not be a practical test of readiness for higher training in the case of ODTS trainees.

We would suggest the following changes in the scheme. First, overseas trainees with a postgraduate qualification from their own country (preferably equivalent to the Membership of the College) should be selected for the scheme. Second, the training in Britain should be limited to the maximum of three years. This would comprise a period of six months to one year in general professional training. After this period their competence for higher training can be assessed on the basis of performance during general professional training or by any other criteria (e.g. The Royal College of Surgeon's requirement for writing one case report and a commentary for each six months in post, as part of monitoring overseas trainees' progress). On the basis of this assessment trainees should be allowed to proceed to a sub-speciality in which they need higher training.

These changes would ensure that ODTS will be able to achieve its main objective, 1.e. appropriate preparation of overseas trainees for work in their own countries, an aim which is difficult to achieve in the present format of general professional training.

\section{References}

Faroog, S. (1994) Overseas Doctors Training Scheme Should take better qualified doctors for shorter periods. British Medical Joumal, 309, 607.

Holman, D. S. (1994) Overseas Doctors Training Scheme Fine tuning required. British Medical Journal, S09, 607.

ROYAL COLLEG OF PSYCHIATRISTS (1994) Statement of Training Scheme for general professional training for the MRCPsych. Psychiatric Bulletin. 18, 514-524.

\section{SAEED FAROOQ}

Senior Registrar, Department of Psychiatry. Post Graduate Medical Institute,

Lady Reading Hospital, Peshawar, Pakistan

\section{Malik H. Mubbashar}

Department of Psychiatry, General Hospital. Rawalpindi, Director WHO Collaborating Centre, Pakistan 